\title{
Fluorescent Magnetic Nanoprobes for in vivo Targeted Imaging and Hyperthermia Therapy of Prostate Cancer
}

\author{
Daxiang Cui ${ }^{1}$, Yuedong Han²*, Zhiming $\mathrm{Li}^{3}$, Hua Song ${ }^{1}$, Kan Wang ${ }^{1}$, Rong He${ }^{1}$, Bing Liu ${ }^{1}$, Heliang $\mathrm{Liu}^{4}$, Chenchen \\ Bao1 ${ }^{1}$ Peng Huang ${ }^{1}$, Jin Ruan ${ }^{1}$, Feng Gao', Hao Yang ${ }^{1}$, Hoon Sung Cho5, Qiushi Ren ${ }^{3}$, Donglu Shi1, 5
}

${ }^{1}$ Department of Bio-Nano Science and Engineering, National Key Laboratory of Micro-Nano Fabrication Technology, Institute of Micro-Nano Science and Technology, ${ }^{2}$ Institute for Laser Medicine \& Biophotonics, Shanghai Jiao Tong University, Shanghai 200240, P. R. china ${ }^{3}$ Department of radio-medicine, ${ }^{4}$ Department of Urology, Xijing Hospital, Fourth Military Medical

University, Xi'an, 710032, P. R. China ${ }^{5}$ Department of Chemical and Materials Engineering, University of Cincinnati, Cincinnati, $\mathrm{OH} 45221$, USA

*Corresponding authors. Email:_dxcui@sjtu.edu.cn or yuedonghan@126.com

\begin{abstract}
It has been a challenging task to develop nontoxic nanoprobes for targeted-imaging and selective therapy of prostate cancer. Herein, fluorescent superparamagnetic nanoparticles with a diameter of $50 \mathrm{~nm}$ were conjugated with single-chain Fv antibody against $\gamma$ seminoprotein. The resultant nanoprobes showed highly selective targeting, fluorescent imaging, and magnetic resonance imaging. The cytotoxicity effects were investigated on the prostate cancer cells and solid tumors under in vitro alternating magnetic field irradiation. It was found that the as-prepared nanoprobes did not show signs of toxicity within the used maximal dosage. It was also observed that the tumors implanted in nude mice were significantly reduced in size and disappeared gradually due to thermal treatment. The lifespan of post-therapeutic mice loaded with prostate cancer was considerable prolonged. High-performance singlechain Fv antibody against $\gamma$-seminoprotein-conjugated fluorescent magnetic nanoparticles may have great potential in applications such early detection and localized thermal therapy of prostate cancer.
\end{abstract}

Keywords: Prostate cancer; Fluorescent magnetic nanoparticles; Single-chain Fv antibody against $\gamma$ - seminoprotein; Sluorescent imaging; Magnetic resonance imaging

Citation: D. Cui, et al. Fluorescent Magnetic Nanoprobes for in vivo Targeted Imaging and Hyperthermia Therapy of Prostate Cancer. Nano Biomed Eng 2009; 1(1):61-74. DOI: 10.5101/nbe.v1i1.p61-74

\section{Introduction}

Prostate cancer is the second leading cause of cancer-related deaths, amounting to over 230,000 new cases per year in the USA [1]. About $60 \%$ of patients with early prostate cancer exhibit no symptoms, finally leading to metastasis due to untimely treatment [2]. Novel approaches for early detection and effective therapy will have the most significant influence on clinical management of the patients with prostate cancer. Recent advances in molecular imaging of cancer using biomarker-targeted contrast agents have shown enhanced specificity and sensitivity to in vivo tumor imaging [3-5]. The development of multi-functional nanoprobes with the capabilities of tumor targetedimaging and delivery of therapeutic agents may further advance the abilities in early detection and treatment of prostate cancer [6-7]. For example, $99 \mathrm{mTc}$ radioimaging agents targeting prostate-specific membrane antigen showed significant potential in applications such as localizing prostate cancer masses, monitoring response to therapy, detecting prostate cancer recurrence following surgery, and selecting patients 
for subsequent PSMA-targeted chemotherapy [8]. However, a major challenge in application to tumor targeted-nanoprobes is insufficient tratumoral distribution of the nanoprobes due to disordered tumor vasculatures, low efficiency of the nanoprobes in crossing the endothelium because of large size of antibody, and extensive tumor stroma that limits nanoprobes interacting with tumor cells. To increase the targeting capability of nanoprobes in prostate cancer, it is preferred to use a smaller size of biomarker that is up-regulated in both prostate cancer and metastasis cancer, but is less or non-expressed in normal prostate tissues.

Human $\gamma$-seminoprotein is a specific antigen secreted by prostate cancer, existing in the cells of prostate cancer and metastasis cancer, and is one specific biomarker for prostate cancer [9]. Using I131 labeled monoclonal antibody against human seminoprotein, high sensitivity and specificity to image radioimmunological images of prostate cancer has been achieved [10]. However, after the entry of the mouseoriginated antibody into human body, it will result in human antibody against mouse antibody. Therefore, development of its single chain variable fragment antibody $(\mathrm{ScFv})$ has become more important for viable clinical applications. In our previous work, we successfully cloned the $\mathrm{ScFv}$ antibody gene of human $\gamma$ seminoprotein, and prepared single-chain Fv antibody against $\gamma$-seminoprotein by using RTS [11]. Immunostaining analysis by using the prepared $\mathrm{ScFv}$ antibody against $\gamma$-seminoprotein as first antibody indicated that strong positive staining in prostate cancer cells and metastasis lymph nodes, but not in normal prostate tissues. This observation implies that the $\mathrm{ScFv}$ $\gamma$-seminoprotein antibody may be used as an ideal candidate for specific targeting to prostate cancer by conjugating onto the nanoprobes.

Magnetic nanoparticles have been widely used for hyperthermia [12], and magnetic resonance imaging (MRI), etc. [5, 13]. Because of low toxicity, magnetic nanoparticles own broad application prospects in clinical imaging and therapy [14-15]. Quantum dots have been subject to intensive investigations due to their unique photoluminescent properties and potential applications [16-20]. Quantum dots have been used successfully in cellular imaging [16], and tumor imaging [16] and stem cells labeling [21] as well as metastasis lymph node tracing [22]. These synthesized quantum dots have significant advantages over traditional fluorescent dyes, including better stability, stronger fluorescent intensity, and different colors by controlling their sizes [23]. Therefore, magnetic nanoparticles and quantum dots provide a new functional platform for nanomedicine research and clinical applications.

In this study, the advantages of magnetic nanoparticles and quantum dots were combined with single strain Fv antibody against $\gamma$-seminoprotein for molecular imaging and hyperthermia therapy of prostate can- cer. Critical issues in this research, such as toxicity, targeting, multi-modal imaging, and thermal therapy were addressed by fabricating nanoprobes composed of $\mathrm{ScFv}$ antibody specific for $\gamma$-semi-noprotein and fluorescent magnetic nanoparticles covered quantum dots. The experimental results demonstrate successful targeting and in vivo imaging of the prostate lesions with low toxicity by fluorescent magnetic nanoparticles surface conjugated with the single-chain Fv antibody against $\gamma$ seminoprotein. The results also show markedly inhibition of the tumor growth in nude mice under in vitro alternating magnetic filed irradiation. The as-prepared nanoprobes render the possibility to serve as a universal specific nanoprobe for multi-modal imaging and thermal therapy of prostate cancer.

\section{Materials and Methods}

\subsection{Cell Lines and nude mice and Reagents.}

Human primary prostate cancer cell line $\mathrm{LNCaP}$ cells and human embryonic kidney HEK293 cells were purchased from the ATCC Company. BLAC/c nude mice (5 or 6 weeks old, No. scxk 2007-005) from Shanghai Animal Experiment Center were used. Trypsin, RPMI1640 medium, and fetal calf serum were obtained from the Gibco BRL Company. The following kits were purchased from commercial sources: The Immunohistochemical Staining Kit (Boster Co.), E. Coli Linear Template Generation Set, His-tag kit, and RTS kit (Roche Diagnostics GmbH, Penzberg, Germany). The Cell Counting Kit-8 assay was obtained from Dojindo Laboratories. All other reagents including chemical reagents and mice anti-human $\mathrm{Cd} 34$ monoclonal antibody were purchased from Sigma Company.

\subsection{Preparation of $\mathrm{ScFv}$ antibody against $\gamma$ - seminoprotein}

The single-chain $\mathrm{Fv}$ antibody against $\gamma$-seminoprotein was prepared according to our previous reports [11]. The prepared single-chain $\mathrm{Fv}$ antibody $(\mathrm{ScFv})$ was purified by using Ni-Nta column, and quantified by Uv-Vis spectroscopy, finally was kept in $-20{ }^{\circ} \mathrm{C}$ for usage.

\subsection{Preparation of fluorescent magnetic nano- composites}

Preparation of $\mathrm{Fe}_{3} \mathrm{O}_{4}$ nanoparticles was based on coprecipitation of ferrous and ferric ion solutions (1:2 molar ratio) [17-19]. CdTe nanocrystals were synthesized as follows according to our previous report [19]: $\mathrm{CdCl}_{2} \cdot 2.5 \mathrm{H}_{2} \mathrm{O}(5 \mathrm{mmol})$ was dissolved in $110 \mathrm{~mL}$ of water, and $12 \mathrm{mmol}$ of TGA were added under stirring, followed by adjusting the $\mathrm{pH}$ to 11 by dropwise addition of $1 \mathrm{M} \mathrm{NaOH}$ solution. The mixed solution was placed in a three-necked flask deaerated by $\mathrm{N}_{2}$ bubbling for $30 \mathrm{~min}$. Under stirring, $2.5 \mathrm{mmol}$ of oxygenfree NaHTe solution was injected into the three-necked flask, which was freshly prepared from tellurium pow- 
der and $\mathrm{NaBH}_{4}($ molar rate of $1: 2)$ in water at $0{ }^{\circ} \mathrm{C}$. The resulting solution was about $4 \mathrm{mg} / \mathrm{mL}$, and the $3.5 \mathrm{~nm}$ diameter product emitted with a maximum around 570 $\mathrm{nm}$. Fluorescent magnetic nanoparticles(FMCNPs) were prepared using the reverse microemulsion approach [18-19]. Typically, $50 \mathrm{~mL}$ cyclohexane, $10 \mathrm{~mL}$ Triton X-100, $8 \mathrm{~mL}$ n-hexanol, $500 \mu \mathrm{L}$ CdTe stock solution, $500 \mu \mathrm{L} \mathrm{Fe}_{3} \mathrm{O}_{4}$ stock solution, and $500 \mu \mathrm{L}$ TEOS were added in a flask in turn under vigorous stirring. After thirty minutes from the formation of the microemulsion, $150 \mu \mathrm{L}$ ammonia aqueous solution was introduced to initiate the polymerization process. The silica growth was completed after $24 \mathrm{~h}$ of stirring. The solution was dealt with by magnetic separation, and the supernatant fluid was discarded. The resultant composite nanoparticles were washed with ethanol and water to remove any ultrapure water. Then, to functionalize the surface of the composite nanoparticles, $9.5 \mathrm{~mL}$ ethanol and $2 \mathrm{~mL}$ APS were added to form a mixed solution and allowed to react at $80{ }^{\circ} \mathrm{C}$ for $3 \mathrm{~h}$. The aminosilane-modified nanoparticles were separated by a permanent magnet again and were washed with water for several times. Finally, FMNPs were obtained and redispersed in $3 \mathrm{~mL}$ water.

\subsection{Preparation and characterization of nanoprobes composed of ScFv antibody and FMNPs}

Fluorescent superparamagnetic nanoparticles (FMNPs, $0.5 \mathrm{~mL}$ of $2 \mathrm{mg} / \mathrm{mL}$ ) were prepared by magnetic separation and washing with PBS $(\mathrm{PH}=7.4)$ solution twice. It was subsequently dispersed in $1 \mathrm{~mL}$ glutaraldehyde solution. The solution was kept in a fully decentralized state by ultrasound for $3 \mathrm{~h}$. Magnetic particles were then separated and washed for three times with PBS, and then, resuspended in solution of $0.5 \mathrm{~mL}$ PBS with. $\gamma$-seminoprotein-specific single-chain antibody $\mathrm{scFv}$ peptide $(400 \mu \mathrm{L}, 2 \mathrm{mg} / \mathrm{mL}$ ) were then added for reaction at $4{ }^{\circ} \mathrm{C}$ for $24 \mathrm{~h}$. The FMNPs-ScFv nanoprobes were obtained with a magnetic separation. The sample was freeze-dried for further experiments. The as-prepared nanoprobes were characterized by high-resolution transmission electron microscopy (TEM JEM2010, at $200 \mathrm{kV}$ ), fluorescence spectrophotometer (Perkin Elmer LS 55 spectro-fluorimeter), and the magnetometer (PPMS-9 T).

\subsection{Cytotoxicity of nanoprobes}

The Cell Counting Kit-8 assay was used to measure cytotoxicity of the synthesized nanoprobes. HEK293 cells without overexpression of $\gamma$-seminoprotein were selected as negative control. The human prostate cancer $\mathrm{LNCaP}$ cells with positive expression of $\gamma$ seminoprotein were selected as target cells. Both cell lines were cultured in RPMI1640 culture medium in the incubator with $5 \% \mathrm{CO}_{2}$ at $37{ }^{\circ} \mathrm{C}$. Culture medium was exchanged every two days. The different concentration of nanoprobes and FMNPs were added into the medium, respectively, and continued to culture for 1-4 $\mathrm{d}$, then cell proliferation inhibition were analyzed [24].

Animal experiment was also used to evaluate the toxicity of as-prepared nanoprobes, which was performed according to Guidelines for Animal Care and Use Committee, Shanghai Jiao Tong University [25]. Thirty nude mice were divided into two groups, 25 nude mice were used as a test group, and five nude mice were used as a control group. As-prepared nanoprobes with 400 pmol dose were injected into nude mice in the test group via tail vessels, and nude mice were sacrificed at two weeks after injection. Blood samples were collected for detection of the amount of prepared nanoprobes. Organs including heart, liver, spleen, lung, kidney and brain were examined by using hematoxylin and eosin staining.

\subsection{Cell targeting of nanoprobes}

HEK293 cells and LNCaP cells were cultured in RPMI1640 medium in the incubator with $5 \% \mathrm{CO}_{2}$ at $37^{\circ} \mathrm{C}$ for $2 \mathrm{~d}$. All the cells were collected and implanted onto $18 \mathrm{~mm}$ glass coverslips in a 12-well tissue culture plates and were continued to culture for $3 \mathrm{~d}$. After rinsing the cells 3 times, different amounts of asprepared nanoprobes were added into each dish and incubated for 30 minutes. These cells were rinsed with PBS buffer, fixed with $4 \%$ paraformaldehyde, coated with glycerol, and sealed with another coverslip. Then these cells were observed and imaged by a fluorescnet microscope (Zeiss Axioscope).

\subsection{Selective magnetic thermal therapy of nano- probes}

The cells incubated with and without 400 pmol nanoprobes were exposed to in vitro alternating magnetic field with $63 \mathrm{kHA}$ and $7 \mathrm{KA} / \mathrm{m}$ for 4 min [26-28]. The cell viability was tested by the MTT method [24].

\subsection{Two-mode imaging and selective therapy of na- noprobes}

LNCaP cells $(5 \times 106)$ were injected subcutaneously into the right back flank area of 35 female nude mice (5 to 6 weeks old) [29]. When tumors grew to $5 \mathrm{~mm}$ in diameter, 400 pmol nanoprobes were injected into mice via tail vein. The magnetic resonance imaging (MRI) of mice was carried out by using The MRI PHILIPS 1.5 Tesla system. The animal fluorescence imaging was performed on the Xenogen IVIS 200 [30]. Mice were respectively sacrificed at 3,6,9, and $12 \mathrm{~h}$. Blood samples and organs were collected, and kept in liquid nitrogen. Blood and tissue samples were lysed ; the precipitates were dissolved in $0.5 \mathrm{M} \mathrm{HCl}$. The amount of nanoprobes was measured by inductively coupled plasma mass spectrometry (Thermo, UK).

The prostate cancer cells-bearing mice were randomly divided into three groups: test group (20 mice) (400 pmol nanoprobes plus in vitro magnetic fields); 
control group 1(10 mice) (only $400 \mathrm{pmol}$ nanoprobes), and control group 2 (5 mice) (untreated). When the tumor size reached about $5 \mathrm{~mm}$ in diameter, the nude mice were injected with 400 pmol nanoprobes via tail vein. After $12 \mathrm{~h}$ from injection, the mice in test group were put under in vitro alternating magnetic field with $63 \mathrm{kHZ}$ and $7 \mathrm{KA} / \mathrm{m}$ for 4 minutes, once a week for one month. The tumor sizes were measured every week. Tumor size and mice survivability were monitored for 27 weeks. Then the nude mice were sacrificed, and tumor tissues were taken out for observation. These specimens were prepared into tissue slices. Expression of $\gamma$-seminoprotein were analyzed by immunohistochemical staining using the as-prepared anti- $\gamma$ seminoprotein $\mathrm{ScFv}$ antibody as the first antibody. Micro-vessel density (MVD) [31-32] were analyzed by immunohistochemical staining using silver nanoparticles-labeled mouse anti-human CD34 monoclonal antibody as the first antibody.

\subsection{Data analysis}

All data are presented in this paper as means result \pm S.D. Statistical differences were evaluated using the $\mathrm{t}$-test and considered significance at $\mathrm{P}<0.05$ level. All figures shown in this article were obtained from three independent experiments with similar results. Differences in survival functions were assessed using the log rank test. All analyses were performed using SPSS 14.0 software.

\section{Results}

\subsection{Characterization of FMNPs and nanoprobes}

Figure 1 shows the results of as-prepared FMNPs and nanoprobes characterized by high resolution transmission electron microscopy (HR-TEM), photoluminescent spectra, and magnetic spectra.

As shown in Figure 1A, FMNPs are composed of magnetic nanoparticles and quantum dots coated with silica, showing the core-shell structure. The insert shows that these composite particles have an average diameter of $50 \mathrm{~nm}$. Figure 1B showed that prepared fluorescent magnetic nanoparticles exhibited yellow or green colour, and dispersed well in water solution, Figure $1 \mathrm{C}$ clearly showed that prepared fluorescent magnetic nanoparticles can be absorbed by outside magnet, which fully showed that prepared fluorescent magnetic nanoparticles own strong magnetic properties. Figure 1D shows fluorescence spectra of FMNPs
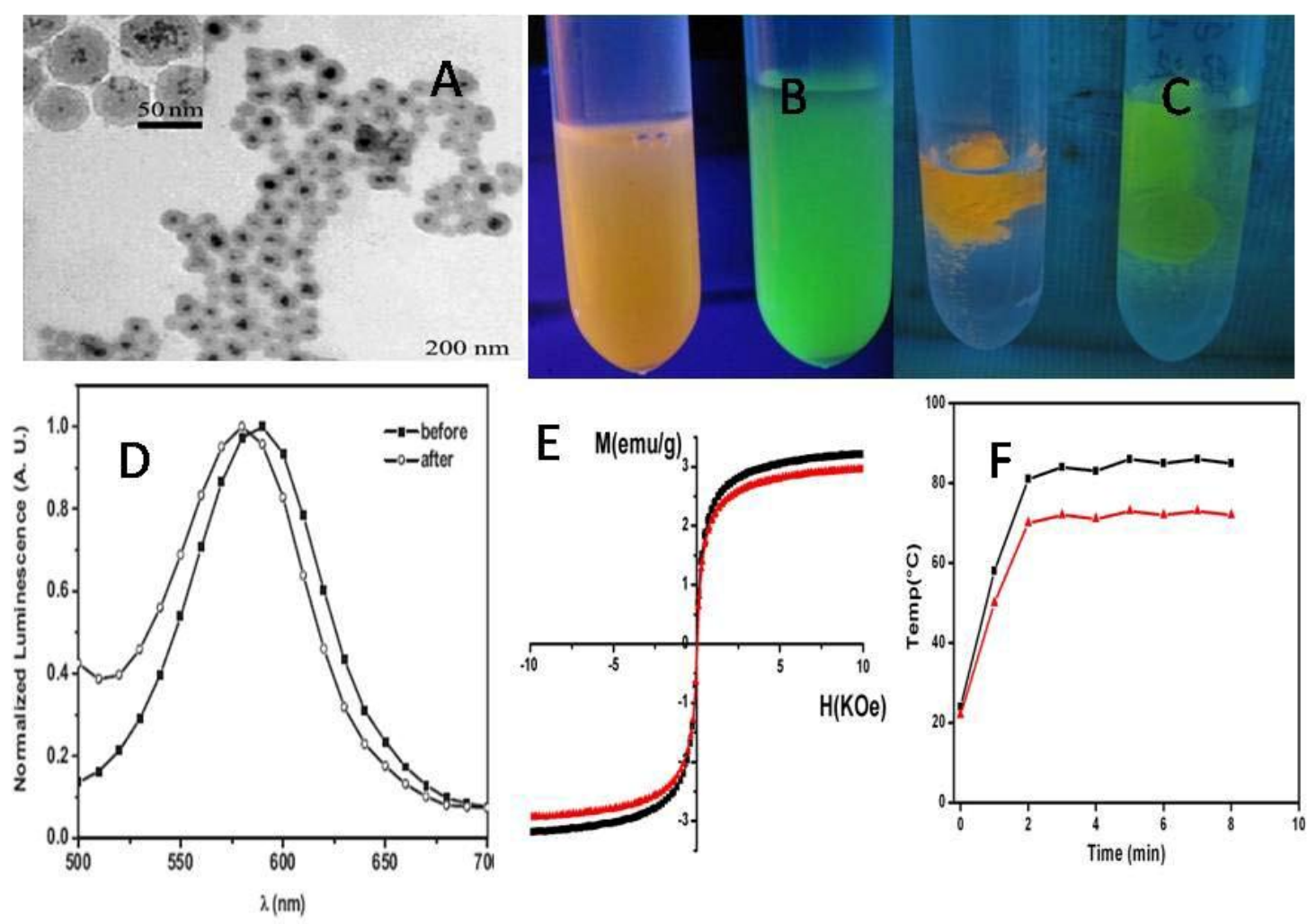

Figure 1. Characterization of as-prepared nanoprobes (A) HR-TEM image of FMCNPs, bar $200 \mathrm{~nm}$, (B) prepared fluorescent magnetic nanoparticles with yellow or green color;(C) aggregated fluorescent magnetic nanoparticles under the magnetic field. (D) Fluorescence spectra of FMCNPs with and without ScFv antibody, (E) Magnetic intensity curve of FMCNPs with and without ScFv antibody at room temperature, (F) Timetemperature curve of as-prepared nanoprobes under an alternating magnetic field with $63 \mathrm{kHZ}$ and $6 \mathrm{kA} / \mathrm{m}$ 
conjugated with and without $\mathrm{ScFv}$ antibody. The amount of bound $\mathrm{ScFv}$ antibody is about $0.8 \mathrm{mg} / \mathrm{mL}$ (or 0.14 $\mu \mathrm{mol} / \mathrm{mL}$ ) nanoprobes. The PL peak after conjugation shows a $5 \mathrm{~nm}$ blue shift. Figure 1E shows the hysteresis curves of FMNPs conjugated with and without $\mathrm{ScFv}$ antibody at room temperature, indicating the superparamagnetic characteristic of the prepared nanoprobes, and $3.24 \mathrm{emu} / \mathrm{g}$ of the magnetic saturation of as-prepared nanoprobes. These results show that the synthesized nanoprobes have both fluorescent and magnetic properties. Figure 1F shows the time-temperature curves of FMNPs and as-prepared nanoprobes under in vitro alternating magnetic field irradiation, indicating that the response temperature of $\mathrm{ScFv}$-antibody-conjugated FMNPs is lower than that of FMNPs.

\subsection{Cytotoxicity and cell targeting of as-prepared nanoprobes}

As shown in Figure 2A, nanoprobes inhibit slightly the growth of prostate cancer LNCaP cells in time-and dose-dependent means. The cell viability is more than $80 \%$ under the condition of as-prepared nanoprobes of 400 pmol for 96 h. For HEK293 cells, as shown in Figure $2 \mathrm{~B}$, the nanoprobes exhibit no significant effect on the cell viability, indicating a low cytotoxicity.

As shown in Figure 2C, D and E, as-prepared
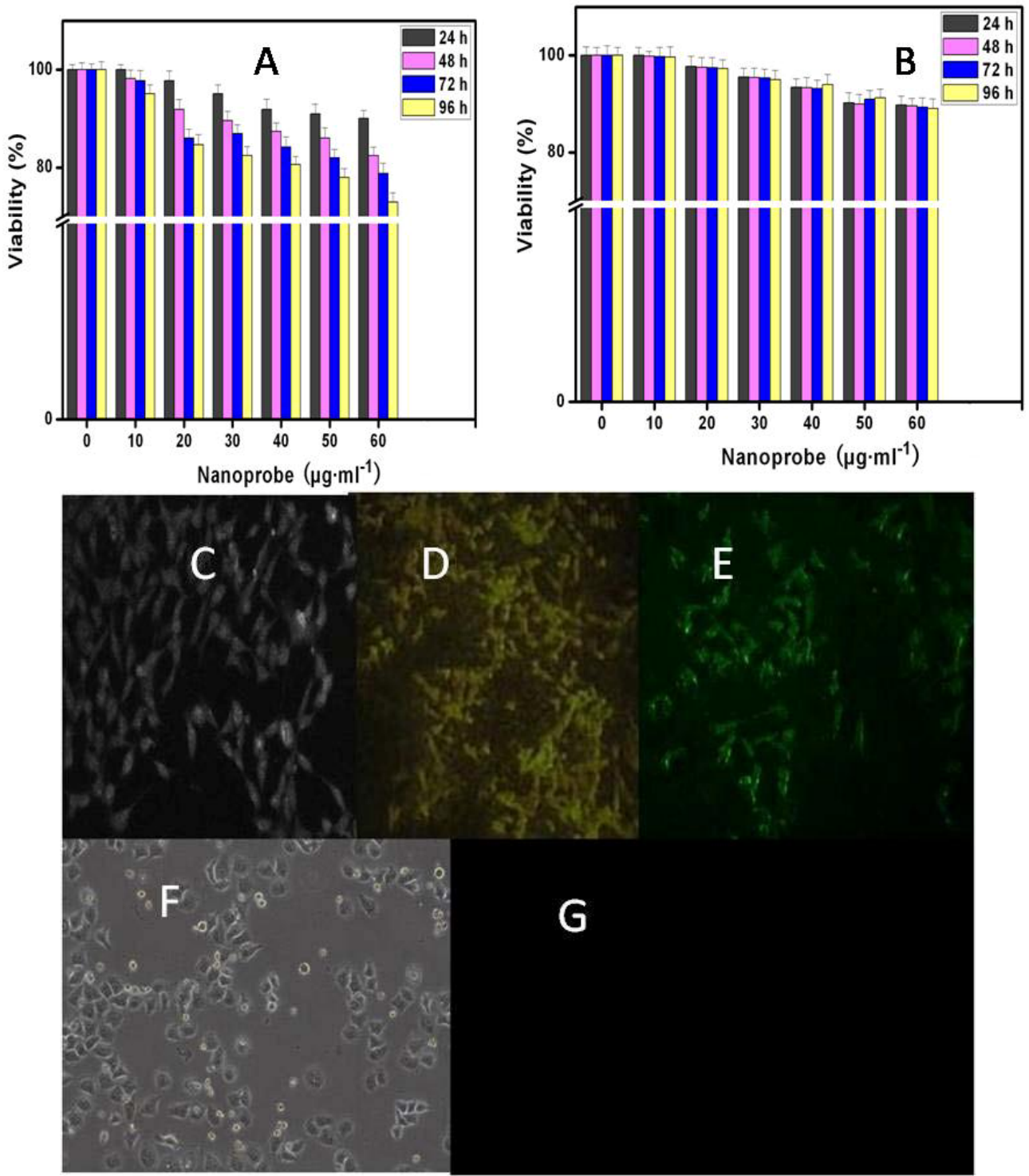

Figure 2. Interaction between nanoprobes and cells. (A) Effects of as-prepared nanoprobes on the viability of prostate cancer LNCaP cells;(B) Effects of as-prepared nanoprobes on the viability of HEK293 cells; (C) image of as-prepared nanoprobes in prostate cancer $\mathrm{LNCaP}$ cells under white light $(\times 20)$; (D and $\mathrm{E}$ ) fluorescent microscope images of as-prepared nanoprobes in prostate cancer LNCaP cells (x20); (F) image of HEK293 cells incubated with as-prepared nanoprobes under white $\operatorname{light}(\times 20)$; (G) fluorescent image of HEK293cells incubated with asprepared nanoprobes. 
nanoprobes can specifically bind with prostate cancer LNCaP cells, and enter into cytoplasm. As shown in Figure $2 \mathrm{~F}$ and $\mathrm{G}$, as-prepared nanoprobes can not bind with HEK293 cells, did not exhibit fluorescent signals. These results fully suggest that as-prepared nanoprobes can specificially target the prostate cancer cells, and own low toxicity.

\subsection{Fluorescent imaging and distribution of nano- probes in nude mice models}

The nude mice models loaded with prostate cancer were successfully prepared. After injection of the nanoprobes into the nude mice, the nanoprobes quickly distribute into heart, liver, spleen, lung, and kidney within $30 \mathrm{~min}$. After $6 \mathrm{~h}$, the nanoprobes gradually concentrate in the tumor tissues; after $24 \mathrm{~h}$, most of nanoprobes disappear in the organs of mice, and are mainly observed in local tumor tissues, as shown in Figure 3A. Figure 3C shows the biodistribution of na- noprobes at different time intervals after injection, which indicates the targeting effects in the tumor tissues after nanoprobe distribution in the system.

Throughout the entire experiment, no entry of nanoprobes into the brain tissues was observed, suggesting an effective blocking mechanism at the blood brain barrier. The control experiment result is shown in Figure 3B, we can clearly observe that FMNPs distributed in the whole body of mice in the whole body of mice include brain, eyes, which fully suggest that asprepared nanoprobes own good specificity.

\subsection{In vivo MRI of nanoprobes in nude mice models}

As shown in Figure 4, in the test group, the nanoprobes begin to concentrate in the local prostate cancer tissues at $6 \mathrm{~h}$ after injection. As a result, the signal of local prostate cancer is gradually enhanced, forming a strong contrast compared with that of the
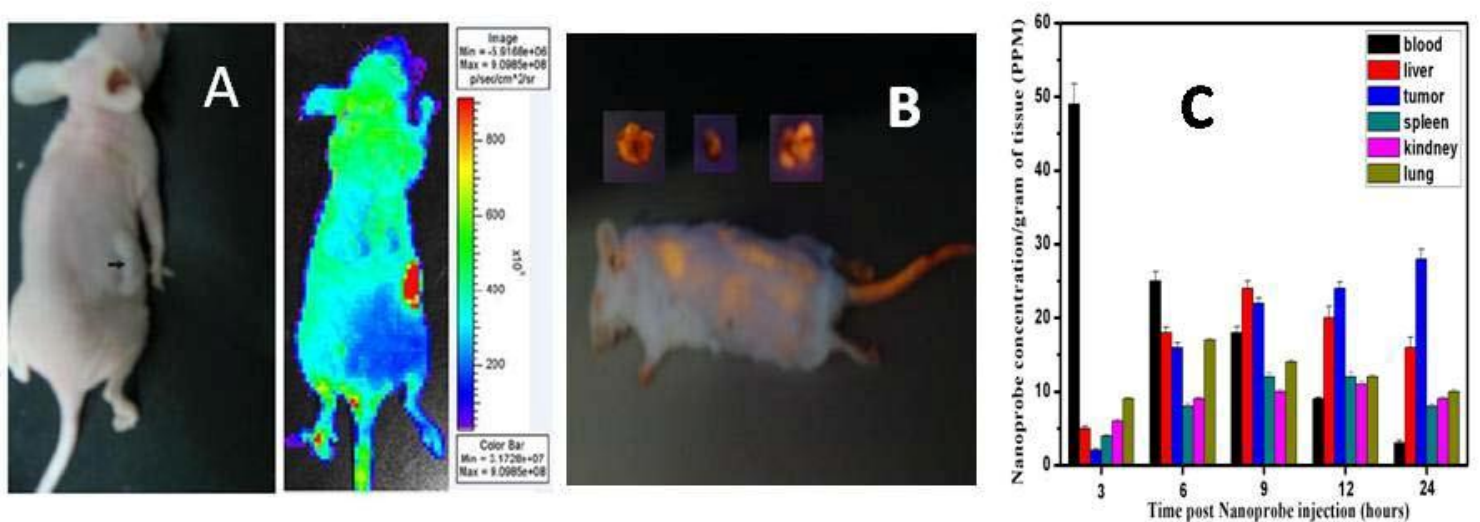

Figure 3. IVIS images of as-prepared nanoprobes in nude mice at $24 \mathrm{~h}$ after injection, respectively. A: mouse with tumor and matched imaging; B: Bio-distribution map of as-prepared nanoprobes in organs and tumor tissues in nude mice at different times after injection.
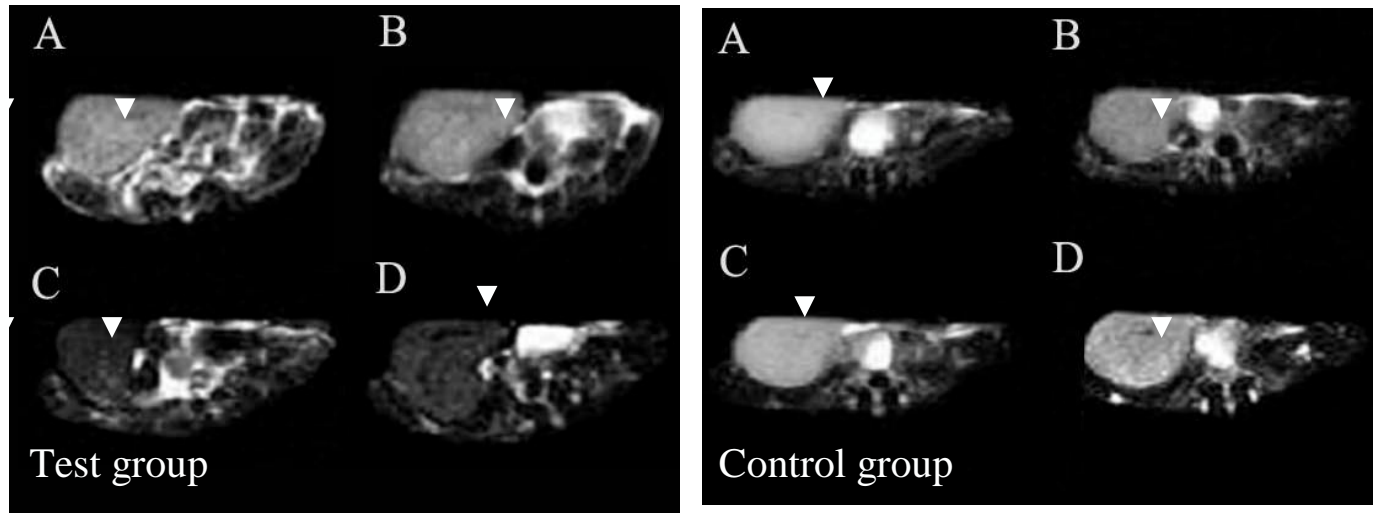

Figure 4. MR images of prostate cancer tissues at different times after as-prepared nanoprobes injection. In the test group, (A) MR image of prostate cancer at 3h after injection; (B) MR image of prostate cancer at $6 \mathrm{~h}$ after asprepared nanoprobes injection; (C) MR image of prostate cancer at $12 \mathrm{~h}$ after injection; (D) MR image of prostate cancer at $24 \mathrm{~h}$ after injection. In the control group, (A) MR image of prostate cancer before injection, (B) MR image of prostate cancer at $6 \mathrm{~h}$ after FMNPs injection; (C) MR image of prostate cancer at $12 \mathrm{~h}$ after FMNPs injection; (D) MR image of prostate cancer at $24 \mathrm{~h}$ after FMNPs injection. 
non-tumor tissues. At $12 \mathrm{~h}$ and $24 \mathrm{~h}$ after injection, respectively, prostate cancer tissues can be distinguished clearly from the normal tissues. FMMNPs are not stabilized with tumor, and quickly cleared from the tumor tissues, so there are no obvious changes observed in the MR images of the tumor tissues, as shown in Figure 4 in the control group. These results are direct and clear evidences of prostate cancer cell targeting by the nanoprobes with a high specificity. Therefore, they can be potentially used as the contrast reagent to enhance the MR signals of prostate cancer.

\subsection{Selective thermal therapy in the prostate cancer cells and nude mice loaded with prostate cancer}

Prostate cancer LNCaP cells incubated with the prepared nanoprobes exhibit cell inhibition effect under the alternating magnetic field irradiation, as shown in Figure 5A. Few damaged cells are observed for the HEK293 cells treated with the identical dose of nanoprobes without the alternating magnetic field irradiation (Figure 5D). Similarly, few death cells are observed for LNCaP cells treated with FMNPs or in vitro magnetic field irradiation (data not shown). These results indicate that as-prepared nanoprobes can, via targeting, specifically kill the prostate cancer cells with over-expressing $\gamma$-seminoprotein under in vitro magnetic field irradiation. Selective thermal therapy of prostate cancer cells can be achieved by the nanoprobes under in vitro magnetic field irradiation. In selective thermal therapy, it was found that the numbers of pros- tate cancer cells destroyed is proportional to the concentration of the nanoprobes in the medium. As shown in Figure 5B, when the concentration of the nanoprobes in the medium is increased up to $400 \mathrm{pmol}$, all cancer cells are killed. Therefore, $400 \mathrm{pmol}$ dose was selected as the therapeutic concentration of nanoprobes for nude mice loaded with prostate cancer.

As shown in Figure 6A, after in vitro alternating magnetic field irradiation, it is observed that the tumor sizes are effectively reduced in the test group compared to that in the control group. The statistical difference between these two groups $(\mathrm{P}<0.05)$ strongly indicate that the nanoprobes can inhibit growth of tumor tissues under in vivo alternating magnetic field radiation. The mean tumor weight in the test group is $423 \pm 101.4 \mathrm{mg}$, but $2042.8 \pm 604.26 \mathrm{mg}$ in the control group. The tumor weight in the test group is markedly lower than that in the control group, which is the statistical difference between these two groups $(\mathrm{P}<0.01)$. It was observed that three tumors in mice almost entirely disappeared in 7 weeks after in vitro magnetic field irradiation as shown in Figure 7.

It was also observed that the mice in the control group mainly died of tumor within 4 weeks, and those in test group still survived within the experiment time of 7 weeks, indicating an effective in vitro alternating magnetic field irradiation by the nanoprobes.

As shown in Figure 6C, there is a high density of micro-vessels in the prostate cancer tissues. After in
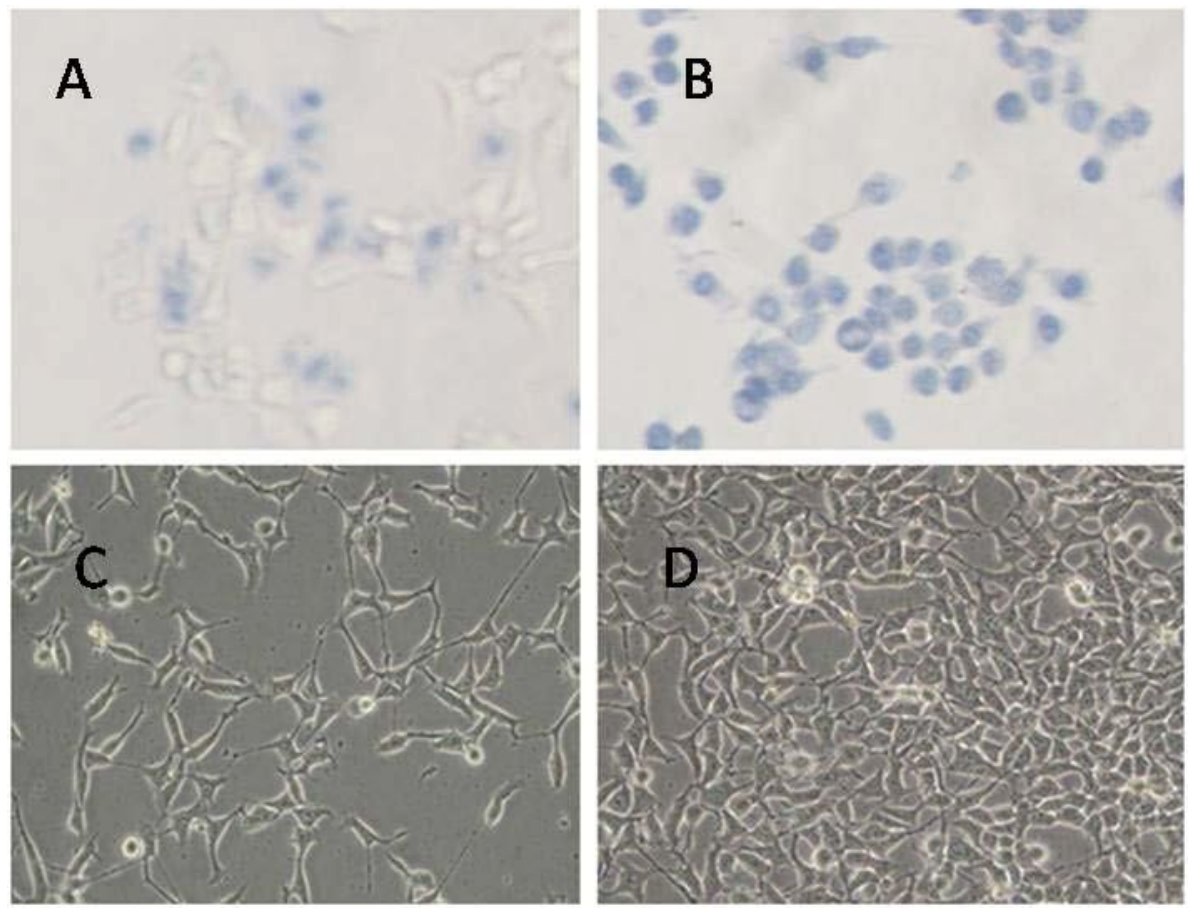

Figure 5. Effects of nanoprobes on LNCaP cells and HEK293 cells under alternating magnetic field irradiation for 4 min. Blue color indicates cell death. (A) LNCaP cells with 40 pmol nanoprobes; (B) LNCaP cells with 400 pmol nanoprobes; (C) LNCaP cells with 20 pmol nanoprobes; (D) HEK293 cells with 400 pmol nanoprobes. 

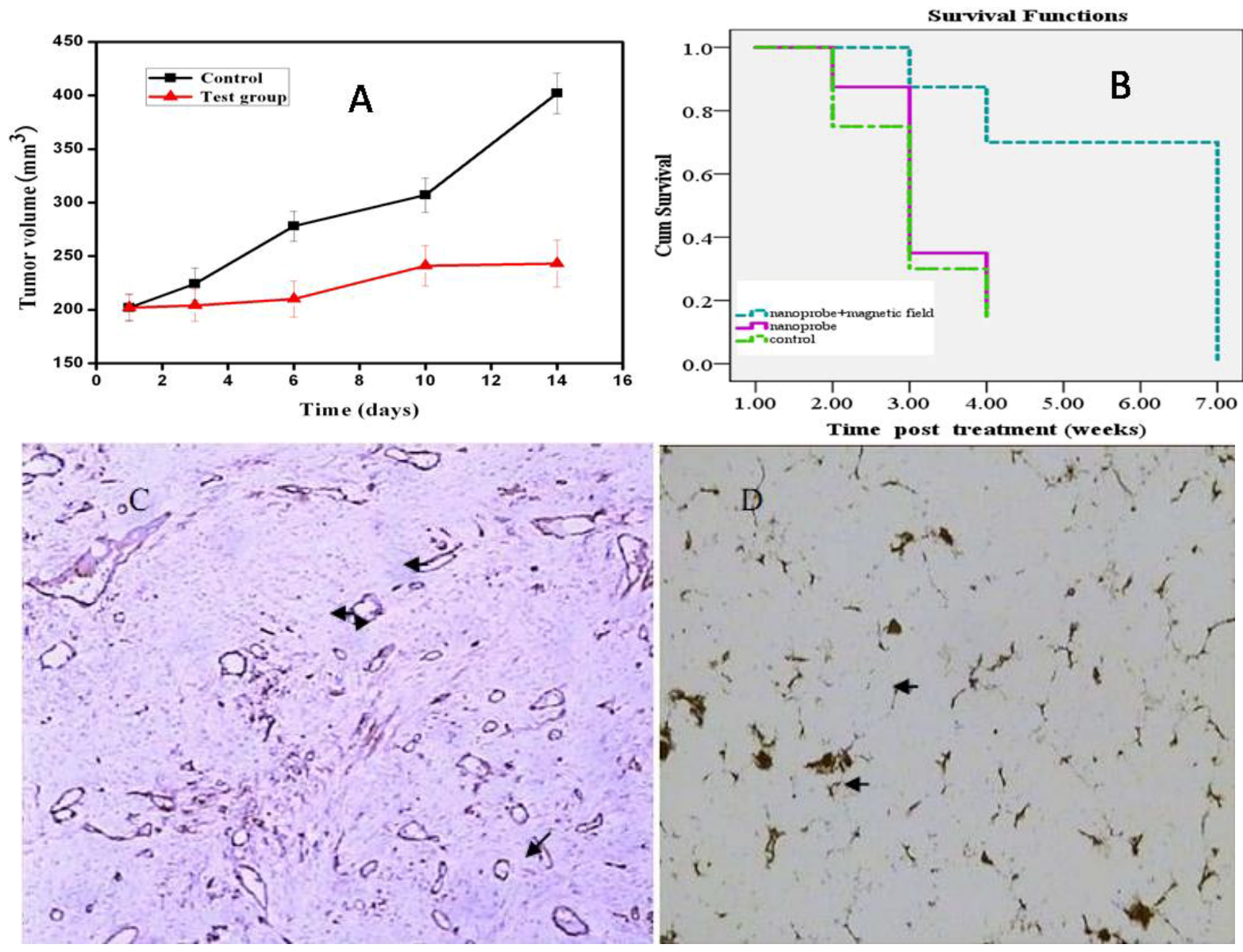

Figure 6. Effects of in vitro alternating magnetic field irradiation on prostate cancer in mice. A: Tumor sizes in the test group and the control group within $14 \mathrm{~d}$; B: Survival time of nude mice under different therapeutic condition; C: Tumor vessels by immunohistochemical staining before therapy; D: Tumor vessels by silver staining after in vitro alternating magnetic field irradiation.

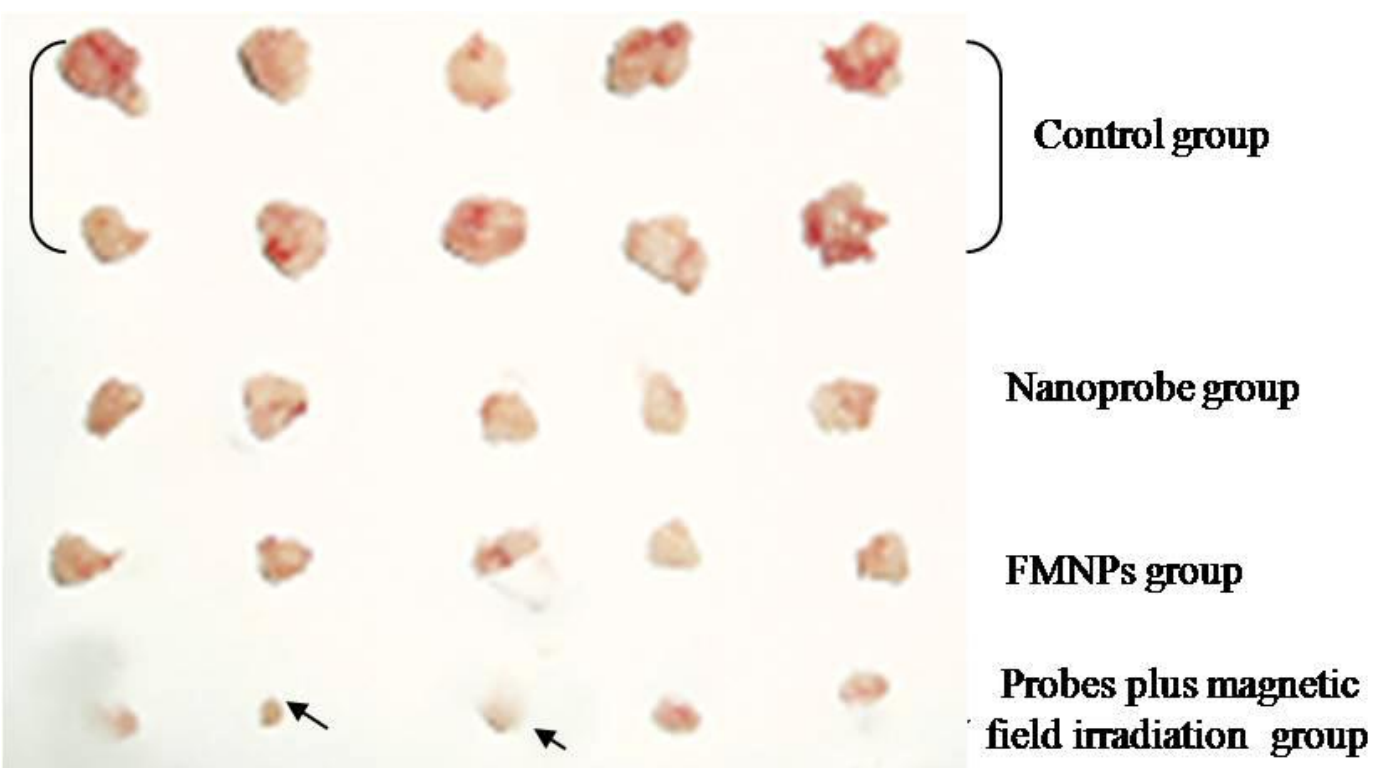

Figure 7. Cancer tissues from test group and control group, 3 tumors (arrow indicated) almost disappeared in test group with nanoprobes plus in vitro magnetic field irradiation for 7 weeks. 
vitro magnetic field irradiation, as shown in Figure 6D, micro-vessels in the tumor tissues are damaged and shrank, leading to reduced vessel sizes. MVD in the test group is $16.2 \pm 2.4$, while that in the control group is $28.2 \pm 6.45$. There is statistical difference between these two groups, $\mathrm{P}<0.01$. These results are consistent with those shown in Figure 6A, suggesting an effective destruction of cancer tissues by selective thermal therapy using the nanoprobes.

\subsection{Effects of as-prepared nanoprobes on important organs in mice loaded with prostate cancer}

As shown in Figure 8, nude mice models loaded with prostate cancer were successfully prepared. The tumor size is almost $0.8 \mathrm{~cm}$ in diameter. As shown in Figure 9, the tumor sample was stained with $\mathrm{ScFv}$ antibody against gamma seminoprotein, exhibiting brown positive staining, which fully suggest that gamma semi- noproteins existed in the tissues of prostate cancer, which lay foundation for targeting prostate cancer.

In order to investigate the specificity of prepared nanoprobes for targeting prostate cancer, we also set up the control experiments. The prepared FMNPs exhibited linear arrays under in vitro magnetic field, the inset showed that the prepared FMNPs displayed good dispersion under no in vitro magnetic field. After FMNPs were injected into mice via tail vein, as shown in Figure 3B, we can observe clearly that FMNPs distributed the whole body in mice, including eye, head, liver, kidney, lung, etc. We also investigated the organ toxicity of asprepared nanoprobes in mice. At two weeks after injection with 400 pmol nanoprobes, mice did not show abnormal changes such as diet, sleep, and movement. The important organs such as brain, lung, heart, liver, and kidney did not show marked pathological changes as shown in Figure 10, showing a low toxicity of the prepared nanoprobes with 400 pmol dose, thus having no
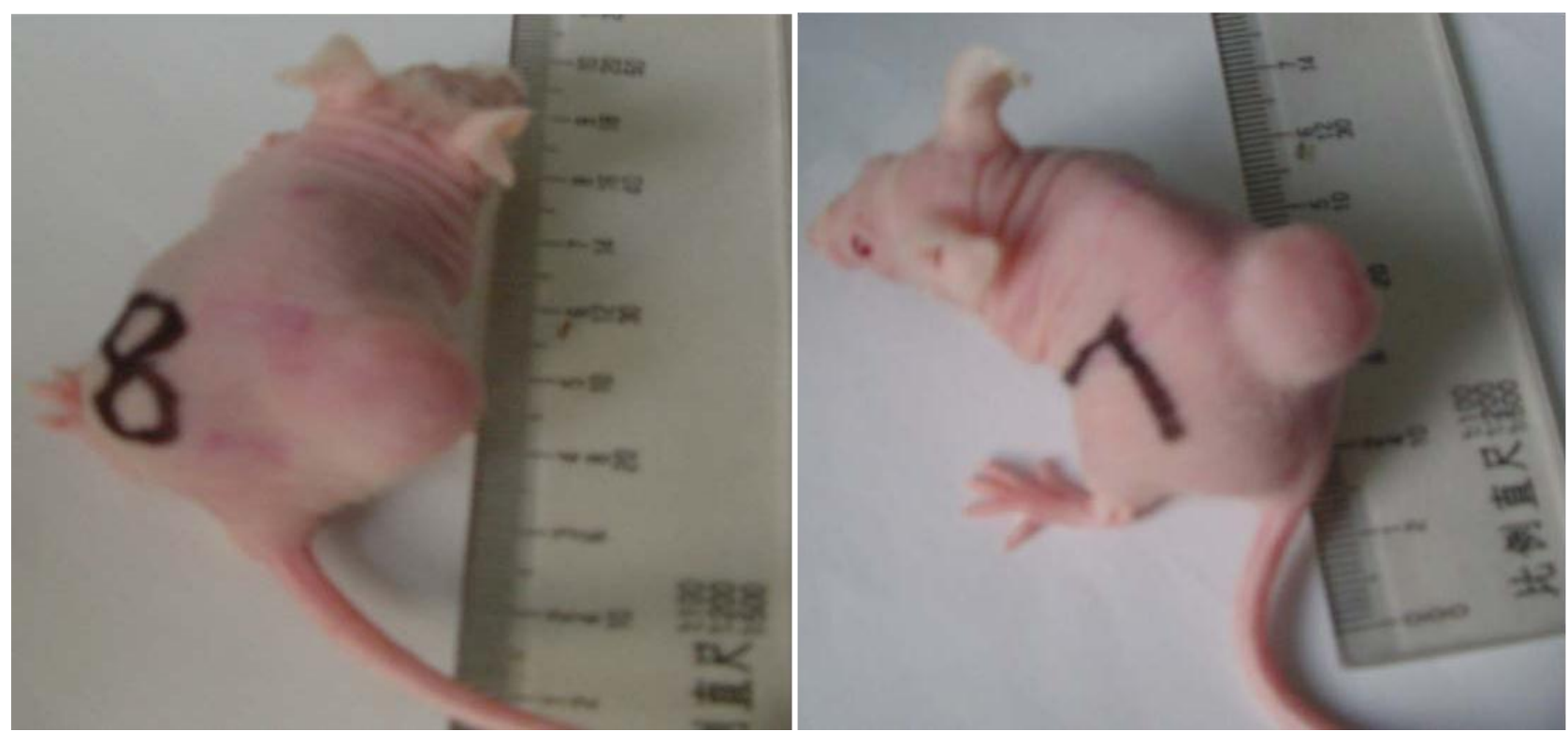

Figure 8. Nude mice models loaded with prostate cancer. The tumor diameter was almost $0.8 \mathrm{~cm}$.

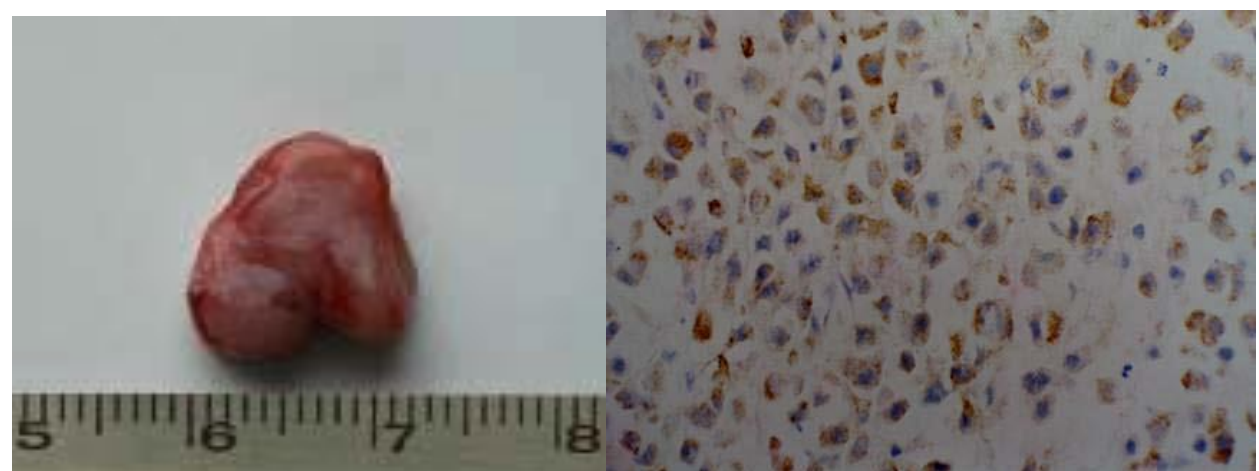

Figure 9. (A) The sample of tumor tissues was from nude mice loaded with prostate cancer. (B) Immunohistochemical analysis result of tumor tissues with antibody against gamma seminoprotein $(\times 100)$, strong positive staining showed the tumor tissues are prostate cancer. 

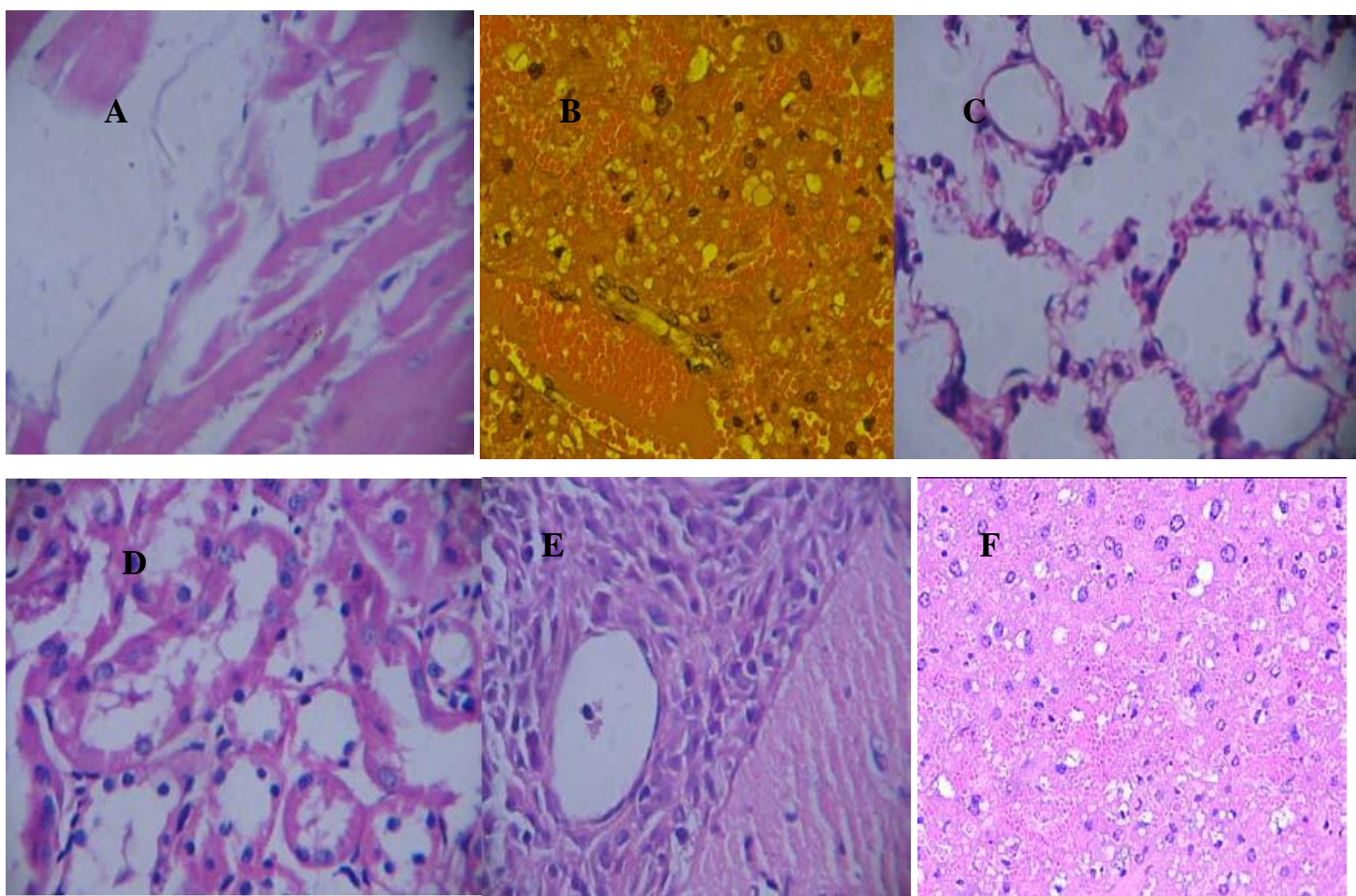

Figure 10. The main organs including heart, liver, lung, kidney and brain from mice treated with 400 pmol nanoprobes for two weeks were stained with HE method $(\times 20)$, no marked pathological changes can be observed. (A) heart. (B)liver, (C) lung, (D) kidney, (E) brain, (F) spleen.

serious toxic effect on the functions of these important organs.

\section{Discussion}

The objective of this study was to develop a novel and versatile nano composite probe, with minimum toxicity, for sensitive detection and localized thermal treatment of malignant lesion in the suspected prostate

cancer patients [33-34]. Some previous reports demonstrated that the magnetic nanoparticles with surface conjugated quantum dots can be used for in vivo twomode imaging in the tumor xenografts [35]. However, the issues on stability and potential toxicity in mice must be addressed [36, 24]. We designed a new nano composite by encapsulating both quantum dots and magnetic nanoparticles in a biocompatible silica sphere, as the so-called fluorescent magnetic nanoparticles (FMNPs). The ScFv antibody-conjugated FMNP nanoprobes exhibit both high luminescence and superparamagnetic moments, meanwhile; with good biocompatibility and stability under different physiological conditions such as serum, blood, various $\mathrm{pH}$ (data not shown) For example, the prepared nanoprobes exhibited low toxic effects on the prostate cancer cells, HEK293 cells, and nude mice, by only distributing in liver, lung, heart and kidney after injection, but not penetrating the blood-brain barrier. Immunostaining analysis shows no obvious organs damage by the nanoprobes. These results demonstrate a good biocompatibility of the nanoprobes, which may serve as the ideal candidates for animal in vivo applications.

Up to date, considerable advances have been made in targeted imaging and therapy of prostate cancer. For example, functional ultrasound, MRI and PET/computed tomography have been used for imaging organ-confined prostate cancer [37-39]. However, the ultrasound suffers from poor accuracy despite significant technical improvements. Most of the recent PET/computed tomography imaging studies rely on choline derivatives (C-11-choline and F-18fluorocholine), their results are promising but insufficient to be currently recommended in routine practice because of expensive cost and radioactivity. Therefore, MRI has marked advantages over functional ultrasound and PET/computed tomography.

Besides generally used to distinguish cancers with extraprostatic metastasis, MRI is now focusing on intraprostatic prostate cancer identification [40]. At 1.5 T, the most recent high-resolution pelvic phased-array coils provide excellent imaging of the whole gland. Improvements in accuracy for cancer detection and volume estimation result from dynamic contrast-enhanced and diffusion-weighted imaging sequences. Histologi- 
cal correlations showed high sensitivity/ specificity for significant volume cancers [41-43]. Therefore, MRI is currently optimal choice for imaging of prostate cancer.

A great deal of reports showed that nanoparticles such as superparamagnetic iron oxide nanoparticles (SPIO) can enhance MRI imaging [44]. These strategies based on SPIO-conjugated specific receptors have been successfully used for imaging of liver cancer [45], breast cancer [46], and pancreatic cancer [47]. In this study, in an effort to enhance the sensitivity of detection of prostate cancer, we achieved high resolution MRI images of prostate cancer by using $\mathrm{ScFv}$-conjugated FMNPs as MRI contrast reagent. At the same time, we also clearly traced the dynamic distribution of prepared nanoprobes in mice, and obtained the clear fluorescence imaging of prostate cancer by using as-prepared nanoprobes and IVIS system. The targeted FMNPsenhanced MRI and fluorescence imaging of prostate cancer markedly improve the sensitivity of detection of prostate cancer, which exhibit great potentials in applications such as early diagnosis of prostate cancer, treatment selection, and clinical planning and outcomes.

Thirdly, in order to investigate the targeting ability of as-prepared nanoprobes, we observed that asprepared nanoprobes can bind with human prostate cancer LNCaP cells, enter into cytoplasm; however, the as-prepared nanoprobes cannot enter into HEK293 cells. These observations suggest that the as-prepared nanoprobes can target human prostate cancer LNCaP cells specifically. We used Xenogen IVIS system and MRI to observe bio-distribution of the as-prepared nanoprobes, and found that they gradually gather in the tumor tissues at $6 \mathrm{~h}$ after injection. At $12 \mathrm{~h}$ and $24 \mathrm{~h}$, respectively, as-prepared nanoprobes mainly congregated on the tumor tissues. The experimental data show that the concentration level of the as-prepared nanoprobes remains at the appropriate level for the maximum therapeutic effects until the termination of the prostate cancer loaded mice. This may lay the clinical foundation for long term thermal therapy based on magnetic nanoparticles. The experimental results also demonstrate that as-prepared nanoprobes can be used for prostate cancer simultaneous two-mode imaging such as fluorescent imaging and magnetic resonance imaging [48], a report for the first time in this study.

In an effort to improve both detection and therapy of prostate cancer, some important advances have been made. For example, Schroeder et al have developed a PSMA-targeted ligand that delivers attached imaging and therapeutic agents selectively to prostate cancer cells without targeting normal cells [49]. Prostate cancer cell-specific VEGF siRNA delivery system using cell targeting peptide conjugated polyplexes has also achieved therapeutic effects [50]. However, thermal therapy is still a very effective method. It is well known that magnetic nanoparticles can be used for thermal therapy under in vitro alternating magnetic field irradia- tion. Thermal therapy owns marked advantages over chemical drug treatment such as smaller tissue damages and controlled therapeutic effects [27-29]. So far some thermal therapy methods have been broadly applied in clinical tumor therapy [26-27]. However, the combined effects from the magnetic nanoparticles and quantum dots in the novel nanoprobe have never been investigated for thermal therapy of prostate cancer. In this research, we measured the magnetic saturation and timetemperature curve of both FMNPs and single chain Fv antibody conjugated FMNPs, resulting in a magnetic saturation of $3.24 \mathrm{emu} / \mathrm{g}$. The time-temperature curve is lower than that of pure FMNPs, but still can produce sufficient heat, giving rise in temperature of $60{ }^{\circ} \mathrm{C}$, higher than $42{ }^{\circ} \mathrm{C}$, at which tumor cells can be effectively killed. Further animal experiments also confirm the feasibility of the ScFv-conjugated FMNP nanoprobes to be used for thermal therapy of prostate cancer. This study provides the first evidence that the nanocomposite of FMNPs is viable for prostate cancer thermal therapy.

Fourthly, in order to investigate the therapeutic effect of the as-prepared nanoprobes as thermal therapeutic reagents for prostate cancer, thermal treatments by alternating magnetic field irradiation was carried out, at the time interval of once a week. The tumor sizes in the test group were effectively reduced. Three implanted tumors almost entirely disappeared. In contrast, the tumor sizes in the control group progressed steadily. A statistical difference between these two groups, $\mathrm{P}<$ 0.01 , was observed. Furthermore, the nude mice in the control group usually died of tumor within 4 weeks. Conversely, nude mice in the test group survived for 7 weeks, showing the effective therapeutic effects on prostate cancer by as-prepared nanoprobes. Our results are consistent with the facts that the heating effects of magnetic nanoparticles in alternating magnetic field can be used for cancer hyperthermia therapy [26-29].

In order to identify the potential therapeutic mechanism, we measured the MVD values in the test group and the control group, for the statistical difference between two groups, $\mathrm{P}<0.01$. This difference is clearly associated with the damaging of the tumor vessels by the as-prepared nanoprobes. However, the contributions may come from several factors including in vitro alternating magnetic field irradiation and blocking of the nutrition supply of tumor tissues. The combined effects lead to slowing down of the tumor growth, as observed.

According to our observations and experimental data, we propose a possible model of interaction between the as-prepared nanoprobes and prostate cancer cells. The ScFv antibody in the as-prepared nanoprobes can bind with $\gamma$-seminoproteins in prostate cancer cells, inducing the endocytosis of as-prepared nanoprobes into cytoplasm. Under the alternating magnetic field irradiation, magnetic nanoparticles in the as-prepared nanoprobes can produce heat energy, and destroying the 
cancer cells. After injection of the as-prepared nanoprobes into the nude mice loaded with prostate cancer via tail vein, in the course of blood circulation, nanoprobes can enter into tumor vessels, and filter into the tumor tissues because of their high penetrability of tumor vessels [51]. The $\mathrm{ScFv}$ antibody in the as-prepared nanoprobes can bind with prostate cancer cells and stay inside the tumor tissues. As the injection time is prolonged, the concentration level of nanoprobes increases on the tumor tissues, while less in the blood stream. As a result of heat effects of the magnetic nanoparticles under an alternating magnetic field, the thermal energy can damage the vessels in the cancer tissues [51], and block the nutrition supply of tumor tissues [52], resulting in slowing down of tumors growth. As the dose of the nanoprobes is maintained at a suitable level in the tumor tissues for a prolong time period, the thermal therapy of prostate cancer can persist until the termination of the mice loaded with prostate cancer.

Although as-prepared fluorescent magnetic nanoprobes like gold nanorods [53], achieved targeted imaging and hyperthermia therapy of prostate cancer in mice model, whether these nanoprobes may be used for human prostate cancer tissues, it is urgently needed to be investigated in near future. Another important concern is the fate of nanoprobes in the body of mice. Up to date, some reports show that nanoparticles such as quantum dots could be filtered by glolerular capillaries in kidney, and excreted via urine as small molecules within five days. Most QDs bound to protein and aggregated into larger particles that were metabolized in the liver and excreted via feces in vivo. After five days, $8.6 \%$ of the injected dose of aggregated QDs still remained in hepatic tissues and it was difficult to clear this fraction of QDs [54]. Our primary results showed that $10-15 \%$ as-prepared nanoprobes can be remained in the body of mice for long time, whether most of nanorpobes were cleared by pathway of kidney or liver excreted via feces in vitro, is still not clarified well, these works are under way in our lab.

In conclusion, fluorescent magnetic nanoparticles with a diameter of $50 \mathrm{~nm}$ were conjugated with singlechain Fv antibody against $\gamma$-seminoprotein. The resultant nanoprobes showed highly selective targeting, fluorescent imaging and magnetic resonance imaging, and selective therapeutic effects on the prostate cancer cells and solid tumors under in vitro alternating magnetic field irradiation. The as-prepared nanoprobes were found to exhibit no obvious toxicity. The tumors implanted in nude mice were effectively reduced; the lifespan of mice loaded with prostate cancer were prolonged. High-performance single-chain $\mathrm{Fv}$ antibody against $\gamma$-seminoprotein-conjugated fluorescent magnetic nanoparticles exhibit great potential in applications such as targeting, simultaneous fluorescent and magnetic resonance imaging, and selective thermal therapy of prostate cancer. The current research mainly focus on further safety issues of as-prepared nanoprobes in the body, and their long-term effects of retention in the body.

\section{Acknowledgement}

This work is supported by China National 973 Project (2010CB933901), National 863 Hi-tech Project (2007AA022004), National Natural Scientific Fund (Nos. 20771075and 30672147), and the science and technology commission Fund of shanghai government (No.072112006 and No.0752nm024). Donglu Shi is grateful to the support from the Institute of Micro-Nano Science and Technology, Shanghai Jiao Tong University, during his sabbatical leave from University of Cincinnati. The authors thank the Instrumental Analysis Center of Shanghai Jiao Tong University for the Materials Characterization.

\section{References}

1. Jemal A, Siegel R and Ward E. Cancer statistics. CA Cancer J Clin 2008; 58: 71-96. doi:10.3322/CA.2007.0010

2. Zeller JL. Grading of prostate cancer. JAMA 2007; 298: 1596. doi:10.1001/jama.298.13.1596

3. Nie S, Xing Y, Kim GJ and Simons JW. Nanotechnology applications in cancer. Annu Rev Biomed Eng 2007; 9: 257288. doi:10.1146/annurev.bioeng.9.060906.152025

4. Weissleder R. Molecular Imaging in cancer. Science 2006; 312: 1168-1171. doi:10.1126/science.1125949

5. Lee J, Hu H, Jun Y, Seo J, Jang J, Song H, et al. Artificially engineered magnetic nanoparticles for ultra-sensitive molecular imaging. Nature Medicine 2007; 13: 95-99. doi:10.1038/nm1467

6. Holves AM, Heesakkers AM. The diagnostic accuracy of $\mathrm{CT}$ and MRI in the pelvis of lymph nodes in patients with prostate cancer: a meta-analysis. Adang Clin Radiol 2008; 63: 387-395.

7. Medarova Z, Pham W, Farrar C, Petkova V and Moore A. In vivo imaging of siRNA delivery and silencing in tumors. Nat Med 2007; 13: 372-377. doi:10.1038/nm1486

8. Kularatne SA, Zhou Z, Yang J, Post CB and Low PS. Design, synthesis and preclinical evaluation of prostatespecific membrane antigen targeted 99mTc-radioimaging agents. Molecular Pharmaceutics 2009; 6: 780-789. doi:1 $\underline{0.1021 / \mathrm{mp} 900069 \mathrm{~d}}$

9. Sasaki R, Habuchi T, Sato K, Akao T, Kakinuma H, Zhang LQ, et al. The clinical utility of measuring total PSA, PSA Density, $\gamma$-seminoprotein and $\gamma$-seminoprotein/total PSA in Prostate Cancer Prediction. Jpn J Clin Oncol 2000 ; 30 : 337-342. doi:10.1093/jico/hyd089

10. Yokota T, Milenic DE, Whitlow M and Schlom1 J. Rapid tumor penetration of a single-chain $\mathrm{Fv}$ and comparison with other immunoglobulin forms. Cancer Res 1992; 52: 3402-3408.

11. Han Y, Huan Y, Deng J, Gao F, Pan B and Cui D. Expression of Single-Chain Fv Gene Specific for gama- 
Seminoprotein by RTS and Its Biological Activity Identification. Biotechnol Prog 2006; 22: 1084-1089. doi:10.1021/bp0504445

12. Kim DH, Lee S H, Kim KN, Kim KM, Shim IB and Lee YK. Cytotoxicity of ferrite particles by MTT and agar diffusion methods for hyperthermic application. J Magn Magn Mater 2005; 293: 287-292. doi:10.1016/j.jmmm.200 $\underline{5.02 .078}$

13. Pan B, Cui D, Sheng Y, Gao F, He R, Li Q, et al. Dendrimer-modified magnetic nanoparticles enhance efficiency of gene delivery system. Cancer Res 2007; 67: 8156-8163. doi:10.1158/0008-5472.CAN-06-4762

14. Sincai M, Ganga D, Ganga M, Argherie D and Bica D. Antitumor effect of magnetite nanoparticles in cat mammary adenocarcinoma. J Magn Magn Mater 2005; 293: 438441. doi:10.1016/j.jmmm.2005.02.074

15. Sincai M, Ganga D, Ganga M, Argherie D and Bica D. Antitumor effect of magnetite nanoparticles in cat mammary adenocarcinoma. J Magn Magn Mater 2005; 293: 438441. doi:10.1016/j.jmmm.2005.02.074

16. Medintz IL, Uyeda HT, Goldman ER and Mattoussi H. Quantum dot bioconjugates for imaging, labelling and sensing. Nature Mater 2005; 4: 435-446. doi:10.1038 $\underline{\text { Inmat1390 }}$

17. Xu P, Cui D, Pan B, Gao F, He R, Li Q, et al. A facile strategy for covalent binding of nanoparticles onto carbon nanotubes. Appl Surf Sci 2008; 254: 5236-5240. doi:10.1016/j.apsusc.2008.02.082

18. He R, You X, Shao J, Gao F, Pan B and Cui D. Core/shell fluorescent magnetic silica-coated composite nanoparticles for bioconjugation. Nanotechnology 2007; 18: 315601. doi:10.1088/0957-4484/18/31/315601

19. You X, He R, Gao F, Shao J, Pan B and Cui D. Nanotechnology 2007; 18: 035701. 이:10.1088/09574484/18/3/035701

20. Alivisatos AP. The use of nanocrystals in biological detection. Nature Biotechnology 2004; 22: 47-52. doi:10.1038/nbt927

21. Bulte JWM, Douglas T, Witwer B, Zhang SC, Strable E, Lewis BK, et al. Magnetodendrimers allow endosomal magnetic labeling and in vivo tracking of stem cells. Nat Biotechnol 2001 ; 19 : 1141-1147. doi:10.1038/nbt1201$\underline{1141}$

22. Burton JB, Johnson M, Sato M, Koh SBS, Mulholland DJ, Stout $\mathrm{D}$, et al. Adnovirus-mediated gene expression imaging to directly detect sentinel lymph node metastasis of prostate cancer. Nature Medicine 2008; 14: 882-888. doi:10.1038/nm.1727

23. Cui D, Pan B, Zhang H, Wang J, Wu R, F Gao, et al. Selfassembly of carbon nanotubes and quantum dots for ultrasensitive DNA and antigen detection. Analytical Chemistry 2008; 80: 7996-8001. doi:10.1021/ac800992m

24. Cui D, Tian F, Ozkan CS, Wang M and Gao H. Effects of single wall carbon nanotubes on human HEK293 cells. Toxicology Letters 2005; 155: 73-85. doi:10.1016/j.toxl et.2004.08.015
25. Cui D, Jin G, Gao T, Sun T, Tian F, Estrada GG, et al. Characterization of BRCAA1 and its novel antigen epitope identification. Cancer Epidemiology, Biomarkers \& Prevention 2004; 13: 1136-1145.

26. Hilger I, Hergt R and Kaiser WA. Towards breast cancer treatment by magnetic heating. J Magn Magn Mater 2005; 293: 314-319. doi:10.1016/j.jmmm.2005.02.026

27. Wang $\mathrm{X}, \mathrm{Gu} \mathrm{H}$ and Yang Z. The heating effect of magnetic fluids in an alternating magnetic field. J Magn Magn Mater 2005; 293: 334-340. doi:10.1016/j.jmmm.2005.02.028

28. Park JH, Im KH, Lee SH, Kim DH, Lee DY, Lee YK, et al. Preparation and characterization of magnetic chitosan particles for hyperthermia application. J. Magn Magn Mater 2005; 293: 328-333. doi:10.1016/j.jmmm.2005.0 $\underline{2.027}$

29. Sharma P and Schreiber-Agus N. Mouse models of prostate cancer. Oncogene 1999; 18: 5349-5355. doi:10.1038/sj.onc. 1203037

30. Lee D, Khaja S, Velasquez-Castano JC, Dasari M, Sun C, Petros $\mathrm{J}$, et al. In vivo imaging of hydrogen peroxide with chemiluminescent nanoparticles. Nature Mater 2007; 6: 765-769. doi:10.1038/nmat1983

31. El-Assal ON, Yamanoi A, Soda Y, Yamaguchi M, Igarashi M, Yamamoto A, et al. Clinical significance of microvessel density and vascular endothelial growth factor expression in hepatocellular carcinoma and surrounding liver: Possible involvement of vascular endothelial growth factor in the angiogenesis of cirrhotic liver. Hepatology 2003; 27: 15541562. doi: $10.1002 /$ hep. 510270613

32. Hogemann D, Ntziachristos V, Josephson L and Weissleder R. High throughput magnetic resonance imaging for evaluating targeted nanoparticle probes. Bioconjug Chem 2002; 13: 116-21. doi:10.1021/bc015549h

33. Ferrari M. Cancer nanotechnology: Opportunites and challenges. Nature Reviews Cancer 2005; 5: 161-171. doi:10.1038/nrc1566

34. Thrall JH. Nanotechnology and Medicine. Radiology 2004; 230: 315-318. doi:10.1148/radiol.2302031698

35. Shi D, Cho HS, Chen Y, Xu H, Gu H, Lian J, et al, Fluorescent Polystyrene- $\mathrm{Fe}_{3} \mathrm{O}_{4}$ Composite Nanospheres for In vivo Imaging and Hyperthermia. Adv Mater 2009; 21: 1-4. doi:10.1002/adma.200803159

36. Rice RF. Nanomaterials show signs of toxicity. Science 2003; 300: 243. doi:10.1126/science.300.5617.243a

37. Puech P, Huglo D, Petyt G, Lemaitre L, Villers A. Imaging of organ-confined prostate cancer: functional ultrasound, MRI and PET/computed tomography. Current Opinion in Urology 2009; 19: 168-176. $\underline{13 \mathrm{e} 328323 \mathrm{f} 5 \mathrm{ed}}$

38. Herschmanh R. Molecular imaging: Looking at problems, seeing solutions. Science 2003; 302: 605-8. doi:10.1 $\underline{126 / \text { science. } 1090585}$

39. Lewin M, Carlesso N, Tung CH, Tang XW, Cory D, Scadden DT, et al. Tat peptide-derivatized magnetic nanoparti 
40. cles allow in vivo tracking and recovery of progenitor cells. Nat. Biotechnol 2000; 18: 410-414. doi:10.1038/74464

41. Jayaprakash S, Wang X, Heston WD and Kozikowski AP. Design and synthesis of a PSMA inhibitor-doxorubicin conjugate for targeted prostate cancer therapy. Chem Med Chem 2006; 1: 299-302. doi:10.1002/cmdc.200500044

42. Tilki D, Seitz M, Singer B, Irmak S, Stief C, Reich O, et al. Molecular Imaging of Tumor Blood Vessels in Prostate Cancer. Anticancer Research 2009; 29: 1823-1829.

43. Weissleder R, Bogdanov A, Neuwelt EA and Papisov M. Long-circulating iron oxides for MR imaging. Adv Drug Deliver Rev 1995; 16: 321-324. doi:10.1016/0169409X(95)00033-4

44. Blasberg RG. Molecular imaging and cancer. Mol Cancer Ther 2003; 2: 335-343.

45. Xu RX, Povoski SP. Diffuse optical imaging and spectroscopy for cancer. Expert Rev Med Devices 2007; 4: 83-95. doi:10.1586/17434440.4.1.83

46. Islam $\mathrm{T}$ and Josephson L. Current state and future applications of active targeting in malignancies using superparamagnetic iron oxide nanoparticles. Cancer Biomarkers 2009; 5: 99-107.

47. Ntziachristos V, Yodh AG, Schnall M, and Chance B. MRI-guided diffuse optical spectroscopy of malignant and benign breast lesions. Neoplasia 2002; 4: 347-354. doi:10.1038/sj.neo.7900244

48. Yang,L, Mao H, Cao Z, Wang Y, Peng X, Wang X, et al. Molecular imaging of pancreatic cancer in an animal model using targeted multifunctional nanoparticles. Gastroenterology 2009; 136: 1514-1525.

doi:10.1053/j.gastro.2009.01.006

49. Medarova Z, Pharm W, Kim Y, and Moore A. In vivo imaging of tumor response to therapy using a dual-modality imaging strategy. Int. J. Cancer 2006; 118: 2796-2802. doi:10.1002/ijc. 21672

50. Schroeder RPJ, van Weerden WM, Bangma C, Krenning EP and de Jong M. Peptide receptor imaging of prostate cancer with radiolabelled bombesin analogues. Methods 2009; 48: 200-204. doi:10.1016/j.ymeth.2009.04.002

51. Kim SH, Lee SH, Tian H, Chen X and Park TG. Prostate cancer cell-specific VEGF siRNA delivery system using cell targeting peptide conjugated polyplexes. Journal of Drug Targeting 2009; 17: 311-317. doi:10.1080/10 $\underline{611860902767232}$

52. Colcher $\mathrm{D}$, bird $\mathrm{R}$, Rosell $\mathrm{M}$. In vivo tumor targeting of a recombinant single-chain antigen-binding protein. J. Natl. Cancer Inst 1990; 82: 1191-1197. doi:10.1093/jnci /82.14.1191

53. Vaupel P, Kallinowski F and Okunieff P. Blood flow, oxygen and nutrient supply, and metabolic microenvironment of human tumors: a review. Cancer Res 1989; 49: 64496455.

54. Li Z, Huang P, Zhang X, Lin J, Yang S, Liu B, et al. RGDConjugated Dendrimer-Modified Gold Nanorods for in vi- vo Tumor Targeting and Photothermal Therapy. Molecular Pharmaceutics 2010, in press. doi:10.1021/mp 9001415

55. Chen Z, Chen H, Meng H, Xing G, Gao X, Sun B, et al. Bio-distribution and metabolic paths of silica coated CdSeS quantum dots. Toxicol Appl Pharmacol 2008; 230 : 364-71. doi:10.1016/j.taap.2008.03.022

Received 10 November, 2009; accepted 6 December, 2009; published online 9 December, 2009.

Copyright: (c) 2009 D. Cui et al. This is an open-access article distributed under the terms of the Creative Commons Attribution License, which permits unrestricted use, distribution, and reproduction in any medium, provided the original author and source are credited. 